\title{
Human Adaptation to the Control of Fire
}

\section{Citation}

Wrangham, Richard W., and Rachel Naomi Carmody. 2010. Human adaptation to the control of fire. Evolutionary Anthropology 19(5): 187-199.

\section{Published Version}

doi:10.1002/evan.20275

\section{Permanent link}

http://nrs.harvard.edu/urn-3:HUL.InstRepos:8944723

\section{Terms of Use}

This article was downloaded from Harvard University's DASH repository, and is made available under the terms and conditions applicable to Open Access Policy Articles, as set forth at http:// nrs.harvard.edu/urn-3:HUL.InstRepos:dash.current.terms-of-use\#OAP

\section{Share Your Story}

The Harvard community has made this article openly available.

Please share how this access benefits you. Submit a story.

\section{Accessibility}


Human adaptation to the control of fire

Richard Wrangham* and Rachel Carmody

Department of Human Evolutionary Biology, Harvard University

11 Divinity Avenue, Cambridge, MA 02138 USA

For Evolutionary Anthropology

* Corresponding Author

Telephone: +1-617-495-5948

Fax: +1-617-496-8041

email:wrangham@fas.harvard.edu

Text Pages: 23 (pp. 3-25)

References: 95 (pp. 26-35)

Figures and Legends: 4 (pp. 36-41)

Text boxes: 1 (pp. 42-45)

Words: 10,479

Key words: cooking, life history, anatomy, behavior, cognition 
About the authors:

Richard Wrangham is a professor in the Department of Human Evolutionary Biology at Harvard University. Since 1987 he has directed a study of chimpanzee behavioral ecology in Kibale National Park, Uganda (currently co-director with Martin Muller). He is the author of Catching Fire: How Cooking Made Us Human (2009, Basic Books). E-mail: wrangham@fas.harvard.edu.

Rachel Carmody is a Ph.D. candidate in Human Evolutionary Biology at Harvard University. Her dissertation focuses on the energetic significance of cooking and non-thermal food processing in human evolution and related consequences for modern human nutrition. E-mail: carmody@fas.harvard.edu. 
Charles Darwin attributed human evolutionary success to three traits. Our social habits

2 and anatomy were important, he said, but the critical feature was our intelligence because it led

3 to so much else, including such traits as language, weapons, tools, boats and the control of fire.

4 Among these, he opined, the control of fire was "probably the greatest ever [discovery] made by

5 man, excepting language." Despite this early suggestion that the control of fire was even more

6 important than tool use for human success, recent anthropologists have made only sporadic

7 efforts to assess its evolutionary significance. ${ }^{\text {e.g. } 1,2}$ Here we use recent developments in

8 understanding the role of cooked food in human diets to support the spirit of Darwin's offhand

9 remark. We first consider the role of fire in increasing the net caloric value of cooked foods

10 compared to raw foods, and hence in accounting for the unique pattern of human digestion. We

11 then review the compelling evidence that humans are biologically adapted to diets that include

12 cooked food, and that humans have a long evolutionary history of an obligate dependence on

13 fire. Accordingly we end by considering the influence of fire on various aspects of human

14 biology. We pay particular attention to life history, and also briefly discuss effects on anatomy,

15 behavior and cognition.

17 The energetic consequences of cooking

18 Foraging serves multiple purposes, including obtaining amino acids, vitamins and

19 minerals, but energy gain is consistently found to be the most important criterion for animal

20 foraging decisions because maximization of energy gain tends to have direct consequences for

21 fitness. ${ }^{3,4}$ This assumption has been validated by numerous studies of primates showing that even

22 small increases in net energy gain lead to increases in female reproductive rate and/or offspring

23 survival, e.g. in humans, ${ }^{5}$ chimpanzees $^{6}$ and baboons. ${ }^{7}$ 
An obvious implication from optimal foraging theory is that like diet choice, patch choice

25 and foraging time, methods of processing food should be designed to maximize energy gain.

26 Among humans the predominant form of food processing is cooking, which has long been

27 known to be a cultural universal that demands time, energy and care (Figure 1). Yet when Lévi-

28 Strauss hypothesized that cooking has no significant biological effects, ${ }^{8}$ no one objected to his

29 idea. Only in the last decade has abundant evidence emerged that cooking consistently increases

30 the energy obtainable from most foods.

31 Two kinds of evidence are particularly informative, though research on both is still at an

32 early stage. First, body weight data show that humans have a more positive energy balance when

33 eating cooked diets compared to when eating raw diets. ${ }^{9}$ In the most extensive study, a cross-

34 sectional survey of 513 long-term raw-foodists living in Germany, Koebnick and colleagues

35 found that body mass index was inversely correlated with both the proportion of raw food in the

36 diet and the length of time since adoption of raw-foodism. ${ }^{10} \underline{\text { All studies of human raw-foodists, }}$

37 and many comparisons of domestic or wild animals on cooked versus raw diets, lead to the same

38 conclusion: the more cooked food in the diet, the greater the net energy gain. ${ }^{9,11}$

39 Second, by studying the effects of cooking specific nutrients, experiments in vivo have

40 begun to reveal the mechanisms underlying the beneficial effects of cooking on energy

41 availability. Until recently researchers generally assumed that raw nutrients such as starch and

42 protein are well digested by humans, given that when humans eat these nutrients raw, very little

43 to none of the nutrient reaches the feces in an undigested form. The inference of $100 \%$

44 digestibility was flawed, however, because studies of ileostomy patients show that both raw

45 starch and raw protein are only partially digested by the time they reach the end of the human

46 small intestine. After leaving the ileum and entering the large intestine, residual nutrients are not 
47 digested by the gut. Instead, they are fermented by intestinal microbes, which consume a

48 proportion of the resulting energy. The proportion of energy that is used by the micro-flora is

49 unavailable to humans, and the fraction of loss to humans ranges from $100 \%$ for protein ${ }^{12,13}$ to an

50 estimated $50 \%$ for carbohydrates. ${ }^{14,15}$ Accordingly, based on the proportion of nutrient digested

51 by the time it reaches the large intestine, cooking appears to increase digestibility substantially.

52 Current experiments suggest that the associated caloric gain due to improved digestibility as a

53 result of cooking is $12-35 \%$ for starches (median $=30 \%$ : oats, wheat, plantain, potato and green

54 banana), and $45-78 \%$ for protein (chicken egg). ${ }^{11}$ The energetic costs of cooking food are

55 currently unmeasured but would have to be very high to negate these benefits. For individuals

56 able to obtain their food cooked without excessive difficulty in finding fuel, defending their

57 fireplace, etc., these effects imply a large fitness advantage.

Cooking also increases net energy gain by reducing the metabolic work performed by

59 humans when digesting. Evidence for this claim comes from animal studies. Other things being

60 equal, rats eating softer food expend less energy in digestion, and are therefore heavier and more

61 obese than rats eating harder diets having the same number of measured calories. ${ }^{16}$ Since

62 cooking consistently softens plant food, ${ }^{9}$ as well as gelatinizes collagen and therefore reduces the

63 physical integrity of meat, ${ }^{17}$ similar effects can be expected due to cooking. Although this

64 hypothesis has not been tested directly in mammals, pythons fed cooked meat were found to

65 experience costs of digestion that were 12-13\% lower than pythons fed equivalent meals of raw 66 meat. $^{18}$

67 Various other mechanisms are potentially important but less well-studied. ${ }^{11}$ Cooked 68 lipids are likely to be digested more easily than raw lipids because they tend to offer a greater 69 surface area for digestion. Cooking may offer important benefits by reducing the energetic costs 
70 of detoxification or of immune defense against pathogens. Cooking also allows more dry weight

71 to be ingested because it reduces water content.

72 Given these energetic benefits of cooking, in addition to other advantages such as making

73 food safer, more accessible and more appetizing, why do people worldwide ever eat any of their

74 diet raw? Two reasons appear particularly important. First, many fruits are designed to be eaten,

75 i.e. they are biologically (and in some cases agriculturally) adapted to being as attractive as

76 possible to consumers (because, in the case of wild fruits, consumers disseminate swallowed or

77 expectorated seeds). The principal attractant is most often sugar, such as in apples and grapes.

78 Cooking presumably does little to increase the digestibility of such items.

79 Second, cooking is sometimes impractical, particularly when individuals are on trek or

80 foraging. For example Australian aborigines would eat a variety of roots, eggs or animals (such

81 as mangrove worms) raw during the day, but if they found enough of the same items to bring

82 them back to camp, they would cook them after reaching home. Likewise Inuit hunters would

83 rarely attempt to cook while foraging, since wood fuel was in short supply and most cooking

84 relied on seal-oil burners that required several hours of use. Inuit men therefore ate various

85 animal foods raw by day, including cached fish and caribou. On return to camp, however, a

86 cooked evening meal was the norm. ${ }^{9}$

\section{Biological adaptation to cooked food}

While most animals, whether wild or domestic, appear to resemble humans by gaining

90 more energy from cooked food than from raw food, current evidence points to a remarkable

91 difference between humans and all other species in the ability to thrive on raw food. Every

92 animal species investigated to date fares acceptably on raw diets. Only humans do not. Thus no 
93 cases are known to us of humans living on raw wild food for more than a few weeks. Raw

94 domesticated food can provide a sustaining diet for contemporary urban raw-foodists, but the

95 few studies of health status all indicate that urban raw-foodists are at risk of chronic energy

96 shortage.

97 Inadequate energy gain from a raw diet probably explains a particularly telling result.

98 Koebnick and colleagues found that most women on a 100\% raw diet were sub-fecund:

99 approximately $50 \%$ of their subjects were amenorrheic. ${ }^{10}$ Indeed, like energy deficiency, the

100 incidence of amenorrhea varied positively with the percentage of raw food in the diet and the

101 duration of raw-foodism (Figure 2). The odds of energy deficiency or amenorrhea were not

102 reduced in subjects who ate animal foods, suggesting that these results were driven by the lack of

103 cooking rather than diet composition. It is notable that reproductive failure occurred in these

104 women even though their urban raw diets had critical energetic advantages over raw diets that

105 hypothetically they might have attempted to consume in the wild. First, since the urban foods

106 were primarily domesticates (both plant and animal), they were likely high in digestible nutrients

107 and low in indigestible components or toxins compared to wild raw foods. Second, the urban

108 raw-foodists would have suffered little seasonal variation in food quality since they obtained

109 food from global sources. Third, raw diets were extensively processed non-thermally (e.g. in

110 blenders) or even by drying over low heat: many raw-foodists treat foods that have been heated

111 below $\sim 46^{\circ} \mathrm{C}$ as acceptable items. Finally, additional advantage appears to come from the urban

112 raw-foodists taking less exercise than foragers.

113 The evidence that the average woman eating a diet of $100 \%$ raw high-quality foods is

114 amenorrheic suggests an important conclusion: human populations are not adapted to survive on

115 a diet of raw wild food, even when it is extensively processed using non-thermal methods. This 
116 idea is consistent with the fact that no human population has ever been found living on raw wild

117 food. The only alternative possibility is that hunter-gatherers in the unknown past were

118 consistently able to find wild raw foods of higher quality than those eaten by contemporary

119 urban raw-foodists. The challenge for those who are skeptical of the importance of cooking in

120 human evolution is therefore to identify such diets. Even though honey, marrow, liver and some

121 exceptional other kinds of meat or fruit or social insect might in theory sustain a population when

122 eaten raw for a few weeks or months, we know of no raw diet that could provide predictable

123 year-round adequacy. Until such a diet has been identified, we conclude that humans differ from

124 all other species in being biologically committed to a diet of cooked food.

125 This proposal is easily understood in terms of our current biology. Most importantly the

126 few available measurements indicate that the intestines of humans are small compared to those of

127 other primates, i.e. around $60 \%$ of the expected weight/volume expected for a species of our

128 body mass. ${ }^{19}$ More data are needed in order to assess the variation in gut dimensions within

129 species, but current information suggests that once our ancestors had predictable access to

130 cooked food, there would have been little benefit in retaining a relatively capacious colon

131 designed to allow fermentation of long-chain carbohydrates. Since gut tissue is energetically

132 expensive to maintain, selection would have favored reduction of colonic tissue and other parts

133 of the gut that were no longer useful for individuals eating a cooked diet.

134 Human molars are also smaller than in other primates. ${ }^{9}$ The action of cooking in reducing

135 food toughness suggests that tooth size reduction is adaptive. ${ }^{20}$ Other features of the mouth that

136 have been interpreted as evolutionary responses to cooked foods include reduction of jaw-muscle

137 myosin, increased salivary amylase production, and reduced oral cavity volume. ${ }^{21}$ 
139 comparative enzymology of the human and ape digestive system, but the relatively high quality

140 of cooked food suggests that human-specific adaptations are likely. Reductions in toxin intake

141 due to the destructive effect of heat may have led to increased sensitivity to plant xenobiotics in

142 humans compared to many primates. Increased ingestion of Maillard compounds (potentially

143 toxic complexes of sugars and amino acids that form under heat catalysis) could have selective

144 consequences for detoxification systems. The ingestion of relatively high calorie loads in meals,

145 particularly late in the day, suggests modifications to the insulin system compared to apes. Such

146 possibilities make the evidence that humans are uniquely adapted to a high-quality diet of cooked

147 food a provocative claim for understanding various aspects of human digestive physiology in a

148 new way.

150 Why Homo erectus appears to have needed fire

151 Given evidence that all humans are biologically adapted to a cooked diet, when did fire

152 use begin? The archeological evidence gives us a minimum age of at least 250 kya. Several sites

153 dated to 250 kya or older contain evidence of fire use by hominids, including burned deposits,

154 fire-cracked rocks, reddened areas, baked clay, ash, charcoal, fire-hardened wood, burned lithics

155 and bone, and even some indication of hearths. ${ }^{22}$ Older dates for fire use are also widely

156 acknowledged at sites such as Beeches Pit in England ${ }^{23}$ and Schöningen in Germany, ${ }^{24}$ dated to

$157 \sim 400 \mathrm{kya}$, as well as Gesher Benot Ya'aqov in Israel, dated to $790 \mathrm{kya}^{25}$ Unfortunately, the

158 archeological record may never tell us when fire was first controlled. There is a decreasing

159 probability of finding evidence of any type as time increases, and this is particularly true with

160 fire use, since traces of fire can vanish quickly. ${ }^{9}$ For example, Sergant and colleagues report that 
161 burnt bone, shells and other artifacts have been found at almost all Mesolithic sites in the

162 northwest European Plain, yet the direct evidence for control of fire is extremely limited. ${ }^{26}$

163 Biology provides an alternative method of inferring the origin of cooking. Animals show

164 that anatomy can adapt very quickly to a change in diet, ${ }^{27,28,29}$ Fast rates are also known for

165 hominins. Among human populations with a history of dairying, lactase persistence (i.e. the

166 ability to digest lactose into adulthood) has evolved at least twice in the last 7,000 years. ${ }^{30,31}$ In

167 addition, populations with a recent history of consuming starch-rich foods exhibit higher copy

168 numbers of the gene encoding for salivary amylase. ${ }^{32}$ Consequently, we can reasonably infer the

169 origin of cooking from the emergence in hominins of biological traits that are consistent with the

170 consumption of cooked food.

$171 \quad$ Predictable effects of cooking, as delineated above, include food softening (including

172 enhanced fracturability) as well as increased digestibility and reduced costs of digestion. From

173 these we can hypothesize that the adoption of cooking should have led to corresponding

174 reductions in masticatory and gastrointestinal anatomy. In what hominin, if any, did such

175 reductions take place?

176 We can eliminate Homo sapiens as a candidate, since fire was almost certainly controlled

177 prior to their emergence $\sim 300-200$ kya and since the anatomical differences from $H$.

178 heidelbergensis were not obviously diet-related, involving primarily a smaller face, rounder head 179 and a somewhat larger brain. ${ }^{33}$

180 Homo heidelbergensis would appear to be a reasonable candidate from an archeological

181 perspective, since its emergence $\sim 800-600$ kya corresponds to the earliest widely accepted date

182 for the control of fire. ${ }^{25} H$. heidelbergensis differs from its precedessor, H. erectus, primarily by

183 its larger cranial capacity and other aspects of cranial shape, including a higher forehead and a 
184 flatter face. ${ }^{9}$ These features are not irrelevant: a less prognathic face can indicate reduced 185 masticatory $\operatorname{strain}^{34}$ and a larger brain suggests a higher energy budget, since the brain is a 186 metabolically expensive tissue. ${ }^{19}$ It is therefore likely that some improvement to the diet did 187 occur at this junction. However, the anatomical changes appear too slight a response to a dietary 188 shift as significant as cooking was likely to have been. In addition, the transition from $H$. erectus 189 to $H$. heidelbergensis appears to have involved no major changes in dentition or gastrointestinal 190 anatomy, in contrast to would be predicted if $H$. heidelbergensis were consuming a cooked diet. 191 By contrast, the transition from late australopithecines or early Homo (Homo habilis, H.

192 rudolfensis) to $H$. erectus is associated with significant changes to diet-related features that are

193 consistent with the predicted effects of a cooked diet. Postcanine tooth area is smaller in

194 H.erectus than in any previous hominin on an absolute basis, and so small as to be equivalent to 195 H. sapiens when adjusted for body size. ${ }^{35}$ Correspondingly, H. erectus also exhibits a relatively 196 smaller mandible ${ }^{36}$ and other aspects of facial shortening, which suggest reduced masticatory 197 strain. ${ }^{34}$ Together, these craniodental features indicate that H. erectus was consuming a softer 198 diet. Gut size also appears to conform to the expected pattern. For instance, H. erectus appears to 199 have had a barrel-shaped thoracic cage, similar to later Homo and distinct from the funnel200 shaped thoraces of previous hominins. ${ }^{37} \mathrm{H}$. erectus is therefore reconstructed as having a smaller 201 gut than its ancestors. ${ }^{19}$ Given consistent trade-offs in gut versus brain size among primates, ${ }^{19}$ 202 larger cranial capacity in H. erectus $\left(849 \mathrm{~cm}^{3}\right)$ compared to H. habilis $\left(601 \mathrm{~cm}^{3}\right)$ or $H$. 203 rudolfensis $\left(736 \mathrm{~cm}^{3}\right)^{35}$ is also consistent with a smaller gut. Despite these reductions in digestive 204 anatomy, H. erectus shows signals of increased energy use, including larger body size, ${ }^{38}$ 205 adaptations for long-distance running, ${ }^{39}$ and possibly reduced interbirth intervals. ${ }^{40}$ The 
apparently softer, more digestible, and higher energy diet of $H$. erectus are all consistent with the 207 expected effects of cooking.

208 Locomotor adaptations likewise point to the control of fire by Homo erectus. It is 209 generally accepted that $H$. erectus was the first obligate biped, with multiple adaptations for

210 terrestrial locomotion that came at the expense of arboreal capability. ${ }^{39,41-44}$ Obligate terrestriality

211 would have exposed $H$. erectus to a broader array of predators, including lions, leopards, hyenas

212 and saber-toothed cats, ${ }^{45}$ with a reduced capacity to scramble up a tree. Whereas $H$. erectus

213 might have defended themselves with weapons during the day, it is hard to imagine how they

214 would have defended themselves at night without the protection of fire. ${ }^{46}$ Indeed, primates

215 almost never sleep terrestrially; the main exceptions are humans, who universally rely on fire for

216 protection in natural habitats; some gorillas (especially adult males), who are probably less

217 susceptible to predation than were H. erectus on account of their larger body size and predator-

218 poor forest habitat; and some cliff-sleeping baboons. ${ }^{47}$ We therefore suggest that the control of

219 fire was a prerequisite for the transition to obligate terrestriality.

221 Adaptive consequences of the control of fire

\section{Life history}

Life history theory predicts causal relationships between age-specific extrinsic mortality

224 rates and the pace of life history. For example, higher extrinsic mortality in adults - due to

225 increased rates of predation or disease - results in a smaller proportion of the population

226 surviving to older age. Increased extrinsic mortality in adults is therefore expected to weaken

227 selection on genetic factors that delay senescence. ${ }^{48,49}$ As a result investments in growth and

228 maintenance are less likely to pay off in terms of increased fecundity. For this reason populations 
229 with higher adult extrinsic mortality tend to evolve fast life history patterns that feature earlier

230 and heavier overall investments in reproduction. Correlated life history traits include shorter

231 gestation, smaller size at birth, earlier weaning, reduced growth period, smaller adult body size,

232 earlier sexual maturity, shorter interbirth intervals, and shorter lifespan. By contrast, species with

233 lower adult extrinsic mortality can afford to allocate more energy to growth and maintenance,

234 selecting for a life history pattern that features slow maturation, increased adult body size, late

235 reproduction, high investment in each of a relatively small number of offspring, and longer life.

236 These relationships have been extensively supported both in the wild ${ }^{50-52}$ and experimentally. ${ }^{53-55}$

237 Compared to other mammals, primates tend to fall along the slow end of the life history

238 continuum, even controlling for body size. ${ }^{56}$ Humans, however, are unique among primates in

239 having a mixed-pace life history (Figure 3). In some respects, humans epitomize the slow

240 strategy. For example, compared to chimpanzees, we birth larger infants, have protracted

241 juvenility (i.e. childhood) and longer adult life expectancy. Yet humans also wean early and

242 reproduce at a much faster rate than would be expected by the pace of our life history. As Dean

243 and Smith describe it, reproduction in humans (hunter-gatherers) "works in double time

244 compared to our closest relatives, the great apes" (p. 115), ${ }^{57}$ with mean interbirth intervals in

245 human foragers being just 2-4 years compared to 5-6 in chimpanzees. ${ }^{58,59,88}$

246 Two main hypotheses have been proposed to explain the unusual combination of slow

247 and fast features in human life history. Both note that humans are evolutionarily committed to a

248 high-quality diet that is difficult to procure. They therefore conclude that weaned juveniles

249 cannot easily feed themselves. As a result, juveniles need to be provisioned by mothers or other

250 kin. $^{58}$ 
The first hypothesis was proposed by Hawkes and colleagues and emphasizes the role of

252 skilled, post-reproductive women in provisioning juveniles and helping with childcare. ${ }^{60}$

253 According to their idea, known as the "grandmother hypothesis," women can add to their

254 inclusive fitness after menopause by facilitating reproductive success in their daughters and other

255 younger kin. In this scenario longer-lived women contribute more to the gene pool via indirect

256 fitness, leading natural selection to favor increased longevity. Interbirth intervals are reduced

257 because the procurement, preparation and provision of appropriate foods by grandmothers means

258 that dependent offspring are weaned sooner; and mothers are better at (and spend less energy in)

259 foraging, facilitating the resumption of menstrual cycling. Hawkes and colleagues suggest that

260 the high fitness benefits of being a grandmother may explain the evolution of postmenopausal

261 longevity in humans. Thus with respect to the life history paradox, the grandmother hypothesis

262 suggests that thanks to certain unique human traits, a long life promotes fast reproduction, and

263 vice versa.

264 The second hypothesis was proposed by Kaplan and colleagues, and emphasizes the age-

265 specific pattern of productivity. According to their idea (the "embodied capital model")

266 productivity of food in adulthood is so high that it can predictably compensate for the negative

267 productivity in early life through the intergenerational transfer of resources. Under this model,

268 longevity is extended because the return from delayed investments increases as the productive

269 life span increases. Interbirth intervals decrease through the system of intergenerational transfers

270 (from any kin, not just grandmothers) that allow women to weight energy allocation toward

271 reproduction rather than food production during their fecund years. Similar logic has also been

272 employed to argue for the inclusive fitness contributions of children and adolescents in shaping

273 the unexpectedly "fast" component of the human life history pattern. ${ }^{61,62}$ 
Here we complement these ideas by proposing that the control of fire and consumption of

275 cooked food also contributed to the evolution of the paradoxical human life history. In our

276 "control of fire hypothesis" the slow components of human life history were favored by two

277 main consequences of using fire. First, fire use led to reduced extrinsic mortality as a result of

278 lower predation and disease. Second, cooking raised the nutritional value of provisioned food,

279 increasing the value of assistance from older individuals and thereby strengthening the selection

280 pressures on senescence. The fast components of human life history, early weaning and short

281 interbirth intervals, were likewise supported by cooking. In our model, earlier weaning was made

282 possible by cooked foods being softer, more easily digestible, and less pathogen-bearing than

283 raw foods. Reduced interbirth intervals were favored by the energetic advantages of a cooked

284 diet and the provisioning that cooking facilitates, allowing for greater stability in the nutritional

285 status of mothers. These ideas are elaborated briefly below. Box 1 summarizes the

286 commonalities and distinctions among the grandmother hypothesis, ${ }^{60}$ embodied capital model, ${ }^{58}$

287 and control of fire hypothesis.

Slow life history via reduced extrinsic mortality and increased productivity in the elderly

290 should theoretically increase extrinsic mortality due to higher rates of predation, disease and

291 environmental hazards on the ground. As expected, a phylogenetically controlled analysis of 776

292 mammalian species found that terrestrial taxa tended to have shorter maximum longevity than

293 arboreal taxa. ${ }^{63}$ Yet despite our terrestriality, modern humans were found to exhibit the highest

294 longevity per body size of any mammal in the dataset, arboreal or terrestrial (Figure 4). This is

295 especially remarkable given that all other terrestrial primates reduce nocturnal predation by

296 sleeping in trees or on cliffs. Aiello and Key proposed that the solution to the problem of 
extended human longevity "most probably lies in the developing social organization and

298 expanding brain that provided a cultural buffer to the elevated mortality risks of the savanna" (p.

299 562). ${ }^{40}$ We suggest that a particularly important 'cultural buffer' was fire use.

300 The control of fire would have reduced extrinsic mortality by at least two means. First,

301 the presence of fire appears to be a powerful deterrent of predators. Although no studies have

302 formally quantified the deterrent effect of fire, demographic data support this claim. For

303 example, causes of 4,993 deaths in a population of 8,008 !Kung hunter-gatherers of the Nyae

304 Nyae area, from ca. 1900 to 2005, were collected systematically by John Marshall, Claire Ritchie

305 and Polly Wiessner, and compiled into a database by Wiessner. Because predator attacks become

306 legendary, Wiessner (pers. comm.) suspects that few, if any, are missing from the record.

307 Wiessner's database includes 10 deaths or serious maulings by lion or leopard from 1910 to

308 1960, all but one of which occurred in the absence of fire. As implied by these data, Wiessner

309 reports that the !Kung regard a night-time fire as importantly protective. Thus, even though

310 getting firewood can be a laborious task, the !Kung normally keep fires going all night and stoke

311 them well when predators are in the vicinity, solely for protection. The danger of sleeping

312 without a fire is illustrated by some of the fatal attacks, such as the death of /Asa: "Her mother

313 and father were sleeping and had let the fire go dead. /Asa was sleeping a short distance away

314 from them. The story goes that lions came and sat by the family, watched the parents, saw /Asa

315 and took her" (P. Wiessner, pers. comm.).

316 Second, control of fire should reduce extrinsic mortality by lowering rates of disease.

317 Controlled burning of campsites controls pest infestations. ${ }^{64}$ In addition, cooking significantly

318 reduces the incidence of foodborne illness, particularly for diets that include meat. ${ }^{11}$ Heat kills

319 the most common foodborne bacteria, including Escherichia coli, Salmonella, Campylobacter, 
Staphylococcus, Listeria, and Clostridium botulinum, all of which are potentially lethal. The

321 incidence of foodborne illness in urban societies arising from meat consumption was recently

322 estimated to be $99.98 \%$ lower due to cooking than if the same meats were consumed raw,

323 suggesting that meat consumption at current levels would be energetically infeasible without

324 cooking. ${ }^{11}$ Finally, the ability of heat to dramatically improve the energetic value of widely

325 available food resources, such as tubers, reduces fluctuations in energy balance that might

326 otherwise compromise immune functions. ${ }^{65}$

327 Importantly, beyond extrinsic factors, fire use can influence the selection pressures

328 governing senescence. Two mechanisms have been proposed for senescence. Mutation

329 accumulation theory, developed by Medawar, states that the force of natural selection weakens

330 with increasing age since extrinsic mortality will lead to fewer individuals alive in older age

331 groups, even in a theoretically immortal population. ${ }^{48}$ Williams observed that antagonistic

332 pleiotropy can also contribute to this effect, since traits that increase fitness early in life but bear

333 a cost later in life will be positively selected for, given that more individuals are alive at young

334 ages than at old ages. ${ }^{49}$ According to these theories, any feature that increases the proportion of

335 individuals surviving to later ages and allows aged individuals to increase their contributions to

336 fitness will strengthen selection on genetic factors that delay senescence, leading to a slowing of

337 life history. We suggest that cooking meets both criteria.

338 For example, it is well established that edentulous or denture-wearing individuals have

339 lower masticatory efficiency than fully dentate individuals. ${ }^{66}$ In addition, masticatory efficiency

340 can be affected by age-related decreases in biting and chewing force, ${ }^{67}$ attributable to

341 deterioration in muscle strength. ${ }^{68}$ Masticatory disability of this type has been shown to increase

342 mortality, even after controlling for other risk factors. ${ }^{69,70}$ By softening foods and reducing their 
343 toughness, cooking should improve the ability of aged individuals to meet their energy needs and

344 thereby increase the proportion of individuals surviving to later ages.

345 In addition, by improving the energetic value of food resources, cooking should increase

346 the advantages of assistance given to reproductive women by grandmothers ${ }^{60}$ and other aged

347 kin. $^{58}$ This increased contribution should lead to slower life history. Under the mutation

348 accumulation model, it would strengthen selection against late-acting deleterious mutations by

349 increasing the contribution to descendant gene pools of longer-lived individuals through the

350 increased reproductive success of their female kin. Under the antagonistic pleiotropy model, it

351 would increase payoffs for late somatic performance and therefore perturb the equilibrium in

352 favor of higher longevity.

$353 \quad$ High fertility via cooked food consumption

354 By transforming plant and animal source foods into nutrient-dense, soft and digestible

355 forms via the mechanisms discussed above, cooking helps make foods accessible to the

356 immature dentition and gastrointestinal tracts of potential weanlings. Moreover, unlike all other

357 forms of processing, cooking reliably kills foodborne bacteria. Studies in developing countries

358 have found that weaning diets are often contaminated with fecal pathogens due to improper food

359 preparation and contact with animal feces, with microbial counts further worsened by prolonged

360 storage at high ambient temperatures, ${ }^{71,72}$ The difficulty of locating fuel for proper cooking or

361 reheating of food has been identified as a key problem hindering the prevention of related enteric

362 infections that are a primary cause of malnutrition among weanlings. ${ }^{73}$ By increasing the

363 availability of suitably nutritious and safe foods, cooking should facilitate weaning, shortening

364 the duration of lactational amenorrhea. 
Beyond lactational amenorrhea, it is well established that the primary ecological

366 mediators of fecundity in women are energetic: net energy balance (i.e. energy stores), energetic

367 expenditure, nutritional intake (i.e. current weight gain/loss) and the energetic costs of lactation

368 are all important. ${ }^{74}$ For example, studies of natural fertility populations have found interbirth

369 intervals to be negatively correlated with maternal post-partum weight, controlling for the

370 duration of lactation. ${ }^{75,76}$ By improving the energetic value of foods - and particularly, starch-

371 rich foods that are consistently available - cooking enables a woman to resume ovarian cycling

372 sooner. Indeed, given the high rates of ovarian suppression observed among female raw-foodists

373 of reproductive age, ${ }^{10}$ we posit that a cooked diet is necessary for routine fertility in female

374 hunter-gatherers.

375 Since cooking improves the nutritive value of foods, fewer raw resources are required to

376 achieve the same benefit. Given the well-established impact of cooking on starchy plant foods,

377 which are the resources routinely collected by women among tropical hunter-gatherers, cooking

378 should substantially lower a woman's foraging effort and increase her own net productivity.

379 Therefore, unlike other models, our scenario for the impact of fire on human life history does not

380 necessarily depend on extra-maternal provisioning of raw food resources or processing effort.

381 Nevertheless, our scenario is highly compatible with extra-maternal provisioning. As discussed

382 by O'Connell and colleagues, this is because the positive effects of cooking increase the

383 efficiency of kin provisioning, thereby broadening the range of provisioners that would achieve

384 commensurate inclusive fitness benefits for their effort. ${ }^{77}$ Moreover, the act of cooking itself

385 represents a means of contribution. This may enable juveniles who are not yet efficient hunters

386 or foragers to contribute meaningfully to kin provisioning and thereby gain inclusive fitness

387 benefits, provided that the inclusive fitness returns justify the costs in terms of time and energy. 
388 Observations of cooking behavior in Hadza juveniles as young as five, though limited to the

389 exploitation of fires kindled by elders ${ }^{77}$ support the idea that contributions are possible even at

390 very early ages. Thus, according to our model, provisioning by grandmothers, grandfathers and

391 juvenile kin can all be expected to play a role in the evolution of the unique human life history

392 pattern.

led to reduction of the digestive system in relation to body mass. Features of the human digestive

397 system that have been reported to be relatively small include teeth, jaw musculature, oral cavity

398 volume, total gut volume, and the surface areas of the stomach, large intestine (colon) and

399 cecum. ${ }^{9,78-80}$ The small intestine is the only major component of the human gut that is close to the 400 expected size (smaller than in $62 \%$ of 42 measured primate species ${ }^{78}$ ), perhaps because it is the 401 major site for nutrient absorption. No gut components are larger than expected. The diminution 402 of the digestive system conforms to humans having a low daily dry weight intake of food 403 compared to non-human primates. ${ }^{81}$ On the other hand, total daily energy expenditure appears 404 high for humans compared to other apes. ${ }^{82}$ The contrast between reduced digestive structures and 405 higher energy use is explicable only by human diets providing exceptional energy.

407 cost of maintaining gut activity, contributes to solving the puzzle of large brains, i.e. the problem 408 of how humans satisfy the high energy demands of a big brain despite having the same relative 409 basal metabolic rate as smaller-brained primates. ${ }^{19}$ Aiello and Wheeler considered that two 410 dietary changes were responsible for reduction of gut costs and corresponding increases in brain 
411 size: more meat around 2 mya, followed by cooking around 0.6 mya. By contrast our argument

412 that cooking likely arose with Homo erectus suggests that cooked food supported the rise in

413 brain size from 1.9 mya onwards. As with many consequences of cooking, other factors may also

414 play a role. In this case, reduction in skeletal muscle may also contribute to explaining how extra 415 energy could be diverted to the brain. ${ }^{83}$

416 The problem of reducing heat loss when inactive suggests a further effect of the control

417 of fire on body hair. As Pagel and Bodmer suggested, the ability to sleep next to a campfire

418 would have solved the problem of maintaining warmth when asleep and therefore allowed the

419 reduction of body hair. ${ }^{84}$ Loss of body hair could be favored by various factors including reduced

420 vulnerability to parasites ${ }^{84}$ and increased ability to lose heat by day, ${ }^{85}$ as well as at least nine

421 other possibilities. ${ }^{86}$ If Wheeler's heat-loss hypothesis is correct, the warmth provided by fire can

422 therefore ultimately be considered vital in enabling humans to acquire the ability to run long

423 distances. Anatomical evidence that long-distance running began with Homo erectus ${ }^{39}$ is thus

424 consistent with the idea that Homo erectus controlled fire. Babies, being relatively inactive by

425 day, would still need to be protected from hypothermia: this might explain why, unlike adults,

426 they have a thick layer of heat-generating fat close to the skin. ${ }^{87}$

\section{Behavior and cognition}

429 One of the most striking behavioral apomorphies of humans is that we spend much less

430 time eating than non-human apes do. Great apes spend 4-7 hours per day chewing, much as

431 expected from their large body mass. By contrast humans spend less than one hour per day

432 chewing according to studies of US residents, Ye'kwana of Venezuela, Kipsigis of Kenya, South

433 Pacific Samoans and nine other societies. ${ }^{9}$ In some ways the abbreviated human chewing pattern 
434 makes us seem like a carnivore, since carnivores spend a similarly small amount of time chewing

435 their food compared to plant-eaters.$^{88}$ However, carnivores achieve their low chewing time by

436 rapidly slicing and swallowing large chunks of meat, unlike the human pattern of finely

437 comminuting their food. The short chewing time of humans is therefore better explained by the

438 effect of cooking and non-thermal processing in reducing the toughness and hardness of food,

439 than by the incorporation of increased amounts of meat in the diet.

440 Low chewing time in humans has several important consequences. Critically, individuals

441 can afford to forego chewing for long periods during the day and instead compress much of their

442 food intake into a relatively brief evening meal. As a result, instead of spending the majority of

443 daylight hours with guts that are actively digesting, humans can minimize gut activity in favor of

444 aerobic exercise. This allows relatively efficient multi-hour locomotion and long day journeys.

445 Thus male chimpanzees have average day-ranges of 3-5 km, with an occasional maximum

446 around $10 \mathrm{~km}$, whereas male hunter-gatherers average around 9-14 km per day. ${ }^{89}$ Such long day-

447 ranges appear to be facilitated by the combination of short chewing times and relatively

448 quiescent guts.

449 Additionally, the fact that humans can eat 2,000+ calories in an hour of chewing means

450 that they can cover their energetic needs even after returning to camp at the end of a largely

451 unproductive day. This depends, of course, on food being available following their return.

452 Among contemporary foragers, the household system means that married men can expect a

453 cooked meal to be available for them every evening. This system, which allows men to forage

454 for high-risk, high-gain food by supporting them nutritionally on days when they fail to produce,

455 thus depends on the use of a food-type that can be consumed rapidly, i.e. cooked food. The 
tendency for men to forage more for high-risk, high-gain foods, while women specialize on low-

457 risk, low-gain foods, therefore, must have been strongly promoted by the control of fire.

458 The relationship between the control of fire and cognitive ability is speculative, but

459 clearly considerable mental ability was important for launching the control of fire. The

460 management of fire requires problem-solving (e.g. to capture fire) and planning (e.g. to get fuel).

461 While chimpanzees and bonobos can control fire in limited ways, ${ }^{9}$ it seems likely that hominin

462 encephalization, possibly as a result of increased meat-eating by habilines, made the stable

463 control of fire cognitively possible. After the control of fire was achieved, life history effects

464 favoring a long period of childhood development would have created further opportunities for

465 enhanced cognitive function. Various consequences would have followed. Even if the initial

466 control of fire did not necessitate a stable home base for weeks at a time, central place foraging

467 was likely adopted to allow both fire-side cooperation in cooking and food distribution, as well

468 as caring for relatively immobile offspring. Reliance on fire also suggests a relatively high level

469 of coordination compared to great apes. Given that great apes demonstrate a preference for

470 cooked food, ${ }^{90}$ we assume that the control of fire would have led rapidly to cooking, which then

471 favored increased patience (to wait until the food is ready), cooperation and respect for

472 ownership (in reducing the problem of scroungers taking food from a poorly guarded fire).

473 Complex co-evolutionary pressures, including social pressures arising both from the opportunity

474 to provision each other and from the ability to steal from each other, therefore seem likely to

475 have shaped the relationship between fire and cognition.

\section{Conclusion}


In this paper we have presented evidence that the first species adapted to the control of

479 fire was Homo erectus. We have also proposed various consequences of using fire, including

480 contributions to the unique patterns of human life history. In some ways we regard these ideas as

481 conforming to existing theory. For instance the hypothesis of early fire use does not challenge

482 the idea that increased meat-eating played an important role in human origins. Nor do we

483 conclude that the lifestyle and life history of $H$. erectus were fully modern. The value of fire to

484 humans and the nature of its use probably changed after fire was first controlled, thanks to

485 advances both in cooking methods and in other ways, such as the effectiveness of fire-based

486 defense against predators. The postulated effects of fire may therefore also have developed in

487 stages. For example while the initial control might have allowed hominids to sleep on the ground

488 without experiencing an increase in predation rates compared to sleeping in trees, fire need not

489 have had any immediate effects in lowering extrinsic mortality. The effects of controlling fire

490 thus need to be considered without assuming that they were always the same as now.

491 Nevertheless, while the consequences of controlling fire have themselves evolved, the

492 acquisition of fire is clearly expected to have had large effects on numerous aspects of human

493 biology, and in some ways our ideas confront conventional wisdom. Thus our hypothesis lies in

494 contrast to the view that fire was controlled first by a relatively late member of the human

495 lineage, i.e. within the last half-million years, since that idea also necessitates the notion that fire

496 use had little impact on human evolutionary biology. Likewise it also challenges the idea that

497 humans are such ecological generalists that they are not adapted to any specific components of

498 their habitats. Potts exemplified a widely held view: "It is patently incorrect to characterize the

499 human ancestral environment as a set of specific repetitive elements, statistical regularities, or

500 uniform problems which the cognitive mechanisms unique to humans are designed to solve" (p. 
501 129)..$^{91}$ By contrast, we claim that humans are biologically adapted to eating cooked food.

502 Accordingly, the human ancestral environment required the presence of controlled fire and

503 cooked meals, and thus presented humans with a specific and consistent set of problems relevant

504 to their biology, behavior and cognition.

505 The cooking hypothesis could be disproved by the discovery of some previously

506 unknown combination of raw, non-thermally processed foods that provides an adequate human

507 diet in diverse and variable habitats. Such a discovery would be provocative and informative. But

508 if the cooking hypothesis is right it presents numerous exciting challenges for understanding the

509 evolutionary impact of the control of fire. Either way, further attention to the unique aspects of

510 human dietary adaptation promises large rewards for understanding human evolution.

511

\section{Acknowledgments}

513 This paper is based on a presentation at the Arizona State University Workshop on

514 Human Uniqueness and Behavioral Modernity (February 19-22, 2010), organized by Kim Hill

515 and Curtis Marean. We thank John Fleagle for the invitation to contribute to Evolutionary

516 Anthropology, Scott Williams and Milena Shattuck for helpful discussion and for sharing their

517 dataset on longevity, Polly Wiessner for data on the sources and contexts of !Kung mortality,

518 Frank Marlowe for documentation on Hadza cooking practices, and Kristen Hawkes, John Shea,

519 John Fleagle and an anonymous reviewer for constructive comments on our manuscript. 


\section{References}

5211 Brace CL. 1995. The Stages of Human Evolution. Englewood Cliffs, NJ: Prentice-Hall.

5222 Burton FD. 2009. Fire: The Spark That Ignited Human Evolution. Albuquerque, NM:

$523 \quad$ University of New Mexico Press.

5243 Pyke GH. 1984. Optimal foraging theory: a critical review. Annu Rev Ecol Syst 15:523$525 \quad 575$.

5264 Stephens DW, Krebs JR. 1986. Foraging theory. Princeton, NJ: Princeton University 527 Press.

5285 Ellison P. 2001. On Fertile Ground. Cambridge, MA: Harvard University Press.

5296 Emery Thompson M, Wrangham RW. 2008. Diet and reproductive function in wild 530 female chimpanzees (Pan troglodytes schweinfurthii) at Kibale National Park, Uganda. $531 \quad$ Am J Phys Anthropol 135:171-181.

5327 Altmann SA. 1998. Foraging for Survival: Yearling Baboons in Africa. Chicago, IL: $533 \quad$ University of Chicago Press.

5348 Lévi-Strauss C. 1970. The Raw and the Cooked. Introduction to a Science of Mythology. 535 I. New York, NY: Harper Row.

5369 Wrangham R. 2009. Catching Fire: How Cooking Made Us Human. New York, NY:

$537 \quad$ Basic Books.

53810 Koebnick C, Strassner C, Hoffmann I, Leitzmann C. 1999. Consequences of a long-term 539 raw food diet on body weight and menstruation: results of a questionnaire survey. Ann $540 \quad$ Nutr Metab 43:69-79.

54111 Carmody RN, Wrangham RW. 2009. The energetic significance of cooking. J Hum Evol $542 \quad 57: 379-391$. 
54312 Mason VC. 1984. Metabolism of nitrogenous compounds in the large gut. P Nutr Soc $544 \quad 43: 45-53$.

54513 McNeil NI. 1988. Nutritional implications of human and mammalian large intestinal 546 function. World Rev Nutr Diet 56:1-42.

54714 Livesey G. 1995. The impact of complex carbohydrates on energy balance. Eur J Clin $548 \quad$ Nutr 49:S89-S96.

54915 Silvester KR, Englyst HN, Cummings JH. 1995. Ileal recovery of starch from whole diets $550 \quad$ containing resistant starch measured in vitro and fermentation of ileal effluent. Am J Clin $551 \quad$ Nutr 62:403-411.

55216 Oka K, Sakuarae A, Fujise T, Yoshimatsu H, Sakata T, Nakata M. 2003. Food texture 553 differences affect energy metabolism in rats. J Dent Res 82:491-494.

55417 McGee H. 2004. On Food and Cooking: the Science and Lore of the Kitchen. New York, $555 \quad$ NY: Scribner.

55618 Boback SM, Cox CL, Ott BD, Carmody R, Wrangham RW, Secor SM. 2007. Cooking 557 and grinding reduces the cost of meat digestion. Comp Biochem Physiol A 148:651-656.

55819 Aiello LC, Wheeler P. 1995. The expensive tissue hypothesis: the brain and the digestive $559 \quad$ system in human and primate evolution. Curr Anthropol 36:199-221.

56020 Lucas P. 2004. Dental Functional Morphology: How Teeth Work. Cambridge: $561 \quad$ Cambridge University Press.

56221 Lucas PW, Ang KY, Sui Z, Agrawal KR, Prinz JF, Dominy NJ. 2006. A brief review of 563 the recent evolution of the human mouth in physiological and nutritional contexts. $564 \quad$ Physiol Behav 89:36-38. 
56522 James SR. 1989. Hominid use of fire in the Lower and Middle Pleistocene: a review of 566 the evidence. Curr Anthropol 30:1-26.

56723 Preece RC, Gowlett JAJ, Parfitt SA, Bridgland DR, Lewis SG. 2006. Humans in the 568 Hoxnian: habitat, context and fire use at Beeches Pit, West Stow, Suffolk, UK. J 569 Quaternary Sci 21:485-496.

57024 Thieme H. 2005. The Lower Paleolithic art of hunting. In: Gamble CS, Parr M, editors. 571 The Hominid Individual in Context: Archaeological Investigations of Lower and Middle 572 Paleolithic Landscapes, Locales and Artefacts. London: Routledge. p 115-132.

57325 Goren-Inbar N, Alperson N, Kislev ME, Simchoni O, Melamed Y, Ben-Nun A, Werker 574 E. 2004. Evidence of hominin control of fire at Gesher Benot Ya'aqov, Israel. Science $575 \quad 304: 725-727$.

57626 Sergant J, Crombé P, Perdaen Y. 2006. The 'invisible' hearths: a contribution to the 577 discernment of Mesolithic non-structured surface hearths. J Archaeol Sci 33:999-1007.

57827 Boback SM. 2006. A morphometric comparison of island and mainland boas (Boa 579 constrictor) in Belize. Copeia 2006:261-267.

58028 Grant PR, Grant BR. 2002. Unpredictable evolution in a 30-year study of Darwin's $581 \quad$ finches. Science 296:707-711.

58229 Gould SJ. 2002. The Structure of Evolutionary Theory. Cambridge, MA: Harvard $583 \quad$ University Press.

58430 Bersaglieri T, Sabeti PC, Patterson N, Vanderploeg T, Schaffner SF, Drake JA, Rhodes 585 M, Reich DE, Hirschhorn JN. 2004. Genetic signatures of strong recent positive selection at the lactase gene. Am J Hum Genet 74:1111-1120. 
58731 Tishkoff SA, Reed FA, Ranciaro A, Voight BF, Babbitt CC, Silverman JS, Powell K, Mortensen HM, Hirbo JB, Osman M and others. 2007. Convergent adaptation of human lactase persistence in Africa and Europe. Nat Genet 39:31-40.

59032 Perry GH, Dominy NJ, Claw KG, Lee AS, Fiegler H, Redon R, Werner J, Villanea FA, 591 Mountain JL, Misra R and others. 2007. Diet and the evolution of human amylase gene 592 copy number variation. Nat Genet 39:1256-1260.

59333 Lieberman DE, McBratney BM, Krovitz G. 2002. The evolution and development of 594 cranial form in Homo sapiens. P Natl Acad Sci 99:1134-1139.

59534 Lieberman DE, Krovitz GE, Yates FW, Devlin M, Claire MS. 2004. Effects of food 596 processing on masticatory strain and craniofacial growth in a retrognathic face. J Hum Evol 46:655-677.

59835 McHenry HM, Coffing K. 2000. Australopithecus to Homo: transformations in body and mind. Annu Rev Anthropol 29:125-146.

60036 Wood B, Aiello LC. 1998. Taxonomic and functional implications of mandibular scaling 601 in early hominins. Am J Phys Anthropol 105:523-538.

60237 Jellema LM, Latimer BM, Walker A. 1993. The rib cage. In: Walker A, Leakey R, 603 editors. The Nariokotome Homo erectus Skeleton. Cambridge, MA: Harvard University 604 Press. p 294-325.

60538 Aiello LC, Wells JCK. 2002. Energetics and the evolution of the genus Homo. Annu Rev 606 Anthropol 31:323-338.

60739 Bramble DM, Lieberman DE. 2004. Endurance running and the evolution of Homo. 608 Nature 432:345-352. 
60940 Aiello LC, Key C. 2002. Energetic consequences of being a Homo erectus female. Am J

$610 \quad$ Hum Biol 14:551-565.

61141 Haeusler M, McHenry HM. 2004. Body proportions of Homo habilis reviewed. J Hum $612 \quad$ Evol 46:433-465.

61342 Jungers WL. 1988. Relative joint size and hominoid locomotor adaptations with

614 implications for the evolution of hominid bipedalism. J Hum Evol 17:247-265.

61543 Walker A, Shipman P. 1996. The Wisdom of the Bones: In Search of Human Origins.

$616 \quad$ New York, NY: Alfred A. Knopf.

61744 Wood BA, Collard M. 1999. The human genus. Science 284:65-71.

61845 Werdelin L, Lewis ME. 2005. Plio-Pleistocene Carnivora of eastern Africa: species

619 richness and turnover patterns. Zool J Linn Soc 144:121-144.

62046 Sabater Pi J, Veà JJ, Serrallonga J. 1997. Did the first hominids build nests? Curr $621 \quad$ Anthropol 38:914-16.

62247 Anderson JR. 2000. Sleep-related behavioural adaptations in free-ranging anthropoid 623 primates. Sleep Med Rev 4:355-373.

62448 Medawar PB. 1952. An Unsolved Problem of Biology. London: H. K. Lewis.

62549 Williams GC. 1957. Pleiotropy, natural selection, and the evolution of senescence.

$626 \quad$ Evolution 11:398-411.

62750 Austad SN. 1993. Retarded senescence in an insular population of Virginia opossums 628 (Didelphis virginiana). J Zool (Lond) 229:695-708.

62951 Harvey PH, Zammuto RM. 1985. Patterns of mortality and age at first reproduction in 630 natural populations of mammals. Nature 315:319-320. 
63152 Promislow DEL, Harvey PH. 1990. Living fast and dying young: a comparative analysis

632 of life-history variation among mammals. J Zool (Lond) 220:417-437.

63353 Luckinbill LS, Clare M. 1985. Selection for life span in Drosophila melanogaster.

$634 \quad$ Heredity 55:9-18.

63554 Ricklefs RE. 1998. Evolutionary theories of aging: confirmation of a fundamental

636 prediction, with implications for the genetic basis and evolution of life span. Am Nat

$637 \quad 152: 24-44$.

63855 Rose M, Charlesworth B. 1981. Genetics of life history in Drosophila melanogaster. II.

639 Exploratory selection experiments. Genetics 97:187-196.

64056 Charnov EL, Berrigan D. 1993. Why do female primates have such long lifespans and so 641 few babies? or life in the slow lane. Evol Anthropol 1:191-194.

64257 Dean CM, Smith BH. 2009. Growth and development of the Nariokotome youth, KNM-

643 WT 15000. In: Grine FE, Fleagle JG, Leakey RE, editors. The first humans: origin and early evolution of the genus Homo. New York, NY: Springer. p 101-120.

64558 Kaplan HS, Hill K, Lancaster JB, Hurtado AM. 2000. A theory of human life history evolution: diet, intelligence and longevity. Evol Anthropol 9:156-183.

64759 Robson SL, Wood B. 2008. Hominin life history: reconstruction and evolution. J Anat 212:394-425.

64960 Hawkes K, O’Connell JF, Blurton Jones NG, Alvarez H, Charnov EL. 1998.

650 Grandmothering, menopause and the evolution of human life history strategies. P Natl 651 Acad Sci 95:1336-1339.

65261 Kramer KL. 2005. Children's help and the pace of reproduction: cooperative breeding in 653 humans. Evol Anthropol 14:224-237. 
65462 Robson SL, van Schaik C, Hawkes K. 2006. The derived features of human life history.

655 In: Paine RL, Hawkes K, editors. The Evolution of Human Life History. Santa Fe, NM:

656 School of American Research Press. p 17-44.

65763 Shattuck MR, Williams SA. 2010. Arboreality has allowed for the evolution of increased

658 longevity in mammals. P Natl Acad Sci 107:4635-4639.

65964 Stewart OC. 1958. Fire as the first great force employed by man. In: Thomas WL, editor.

660 Man's Role in Changing the Face of the Earth. Chicago, IL: University of Chicago Press.

$661 \quad$ p 115-133.

66265 Demas GE. 2004. The energetics of immunity: a neuroendocrine link between energy

663 balance and immune function. Horm Behav 45:173-180.

66466 Nagao M. 1992. The effects of aging on mastication. Nutr Rev 50:434-437.

66567 Tzakis MG, Österberg T, Carlsson GE. 1994. A study of some masticatory functions in

6669 90-year old subjects. Gerodontology 11:25-29.

66768 Newton JP, Yemm R, Abel RW, Menhinick S. 1993. Changes in human jaw muscles

668 with age and dental state. Gerodontology 10:16-22.

66969 Nakanishi N, Fukuda H, Takatorige T, Tatara K. 2005. Relationship between self-

670 assessed masticatory disability and 9-year mortality in a cohort of community-residing

671 elderly people. J Am Geriatr Soc 53:54-58.

67270 Semba RD, Blaum CS, Bartali B, Xue QL, Ricks MO, Guralnik JM, Fried LP. 2006.

673 Denture use, malnutrition, frailty, and mortality among older women living in the

674 community. J Nutr Health Aging 10:161-167. 
67571 Black RE, Lopez de Romaña G, Brown KH, Bravo N, Grados Bazalar O, Creed Kanashiro H. 1989. Incidence and etiology of infantile diarrhea and major routes of

677 transmission in Huascar, Peru. Am J Epidemiol 129:785-799.

67872 Rowland MGM, Barrell RAE, Whitehead RG. 1978. The weanling's dilemma: bacterial 679 contamination in traditional Gambian weaning foods. Lancet 1:136-138.

68073 Brown KH, Bégin F. 1993. Malnutrition among weanlings of developing countries. still a 681 problem begging for solutions. J Pediatr Gastr Nutr 17:132-138.

68274 Ellison PT. 2003. Energetics and reproductive effort. Am J Hum Biol 15:342-351.

68375 Ford K, Huffman SL, Chowdhury AKMA, Becker S, Allen H, Menken J. 1989. Birth684 interval dynamics in rural Bangladesh and maternal weight. Demography 26:425-437.

68576 Huffman SL, Ford KT, Allen HA, Streble P. 1987. Nutrition and fertility in Bangladesh: 686 breastfeeding and post partum amenorrhoea. Pop Stud 41:447-462.

68777 O'Connell JF, Hawkes K, Blurton Jones NG. 1999. Grandmothering and the evolution of $688 \quad$ Homo erectus. J Hum Evol 36:461-485.

68978 Martin RD, Chivers DJ, MacLarnon AM, Hladik CM. 1985. Gastrointestinal allometry in 690 primates and other mammals. In: Jungers WL, editor. Size and Scaling in Primate 691 Biology. New York, NY: Plenum Press. p 61-89.

69279 Milton K, Demment MW. 1988. Chimpanzees fed high and low fiber diets and 693 comparison with human data. J Nutr 118:1082-1088.

69480 Stedman HH, Kozyak BW, Nelson A, Thesier DM, Su LT, Low DW, Bridges CR, 695 Shrager JB, Minugh-Purvis N, Mitchell MA. 2004. Myosin gene mutation correlates with 696 anatomical changes in the human lineage. Nature 428:415-418. 
69781 Barton RA. 1992. Allometry of food intake in free-ranging anthropoid primates. Folia

$698 \quad$ Primatol 58:56-59.

69982 Leonard WR, Robertson ML. 1997. Comparative primate energetics and hominid $700 \quad$ evolution. Am J Phys Anthropol 102:265-281.

70183 Isler K, van Schaik CP. 2006. Costs of encephalization: the energy trade-off hypothesis 702 tested on birds. J Hum Evol 51:228-243.

70384 Pagel M, Bodmer W. 2003. A naked ape would have fewer parasites. P R Soc London $704 \quad 270: S 117-S 119$.

70585 Wheeler P. 1992. The influence of the loss of functional body hair on hominid energy $706 \quad$ and water budgets. J Hum Evol 23:379-388.

70786 Rantala MJ. 2007. Evolution of nakedness in Homo sapiens. J Zool (Lond) 273:1-7.

70887 Kuzawa CW. 1998. Adipose tissue in human infancy and childhood: an evolutionary 709 perspective. Yearb Phys Anthropol 41:177-209.

71088 Shipman P, Walker A. 1989. The costs of becoming a predator. J Hum Evol 18:373-392.

71189 Marlowe FW. 2005. Hunter-gatherers and human evolution. Evol Anthropol 14:54 -67.

71290 Wobber V, Hare B, Wrangham R. 2008. Great apes prefer cooked food. J Hum Evol $713 \quad 55: 340-348$

71491 Potts R. 1998. Environmental hypotheses of hominin evolution. Yearb Phys Anthropol $715 \quad 41: 93-138$.

71692 Harvey PH, Martin RD, Clutton-Brock TH. 1987. Life histories in comparative 717 perspective. In: Smuts BB, Cheney DL, Seyfarth RM, Wrangham RW, Struhsaker TT, 718 editors. Primate Societies. Chicago, IL: University of Chicago Press. p 181-196. 
71993 Charnov EL. 1991. Evolution of life history variation among female mammals. P Natl $720 \quad$ Acad Sci 88:1134-1137.

72194 Charnov EL, Berrigan D. 1990. Dimensionless numbers and life history evolution: age of 722 maturity versus the adult lifespan. Evol Ecol 4:273-275.

72395 Wrangham RW, Jones JH, Laden G, Pilbeam D, Conklin-Brittain NL. 1999. The raw and 724 the stolen: cooking and the ecology of human origins. Curr Anthropol 40:567-594.

725

726

727 
$727 \quad$ Figures

728

$729 \quad$ Figure 1.

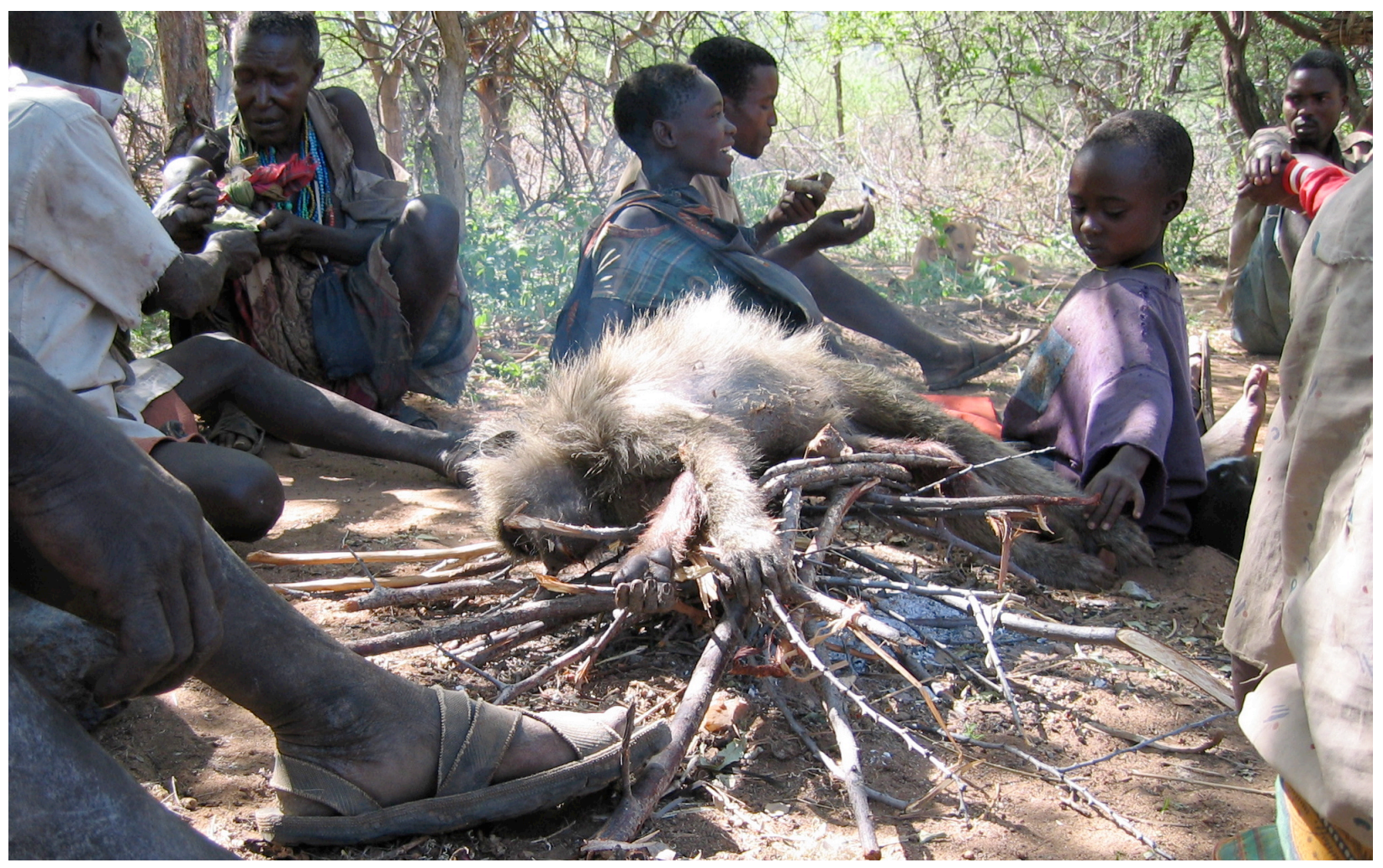


$731 \quad$ Figure 2.

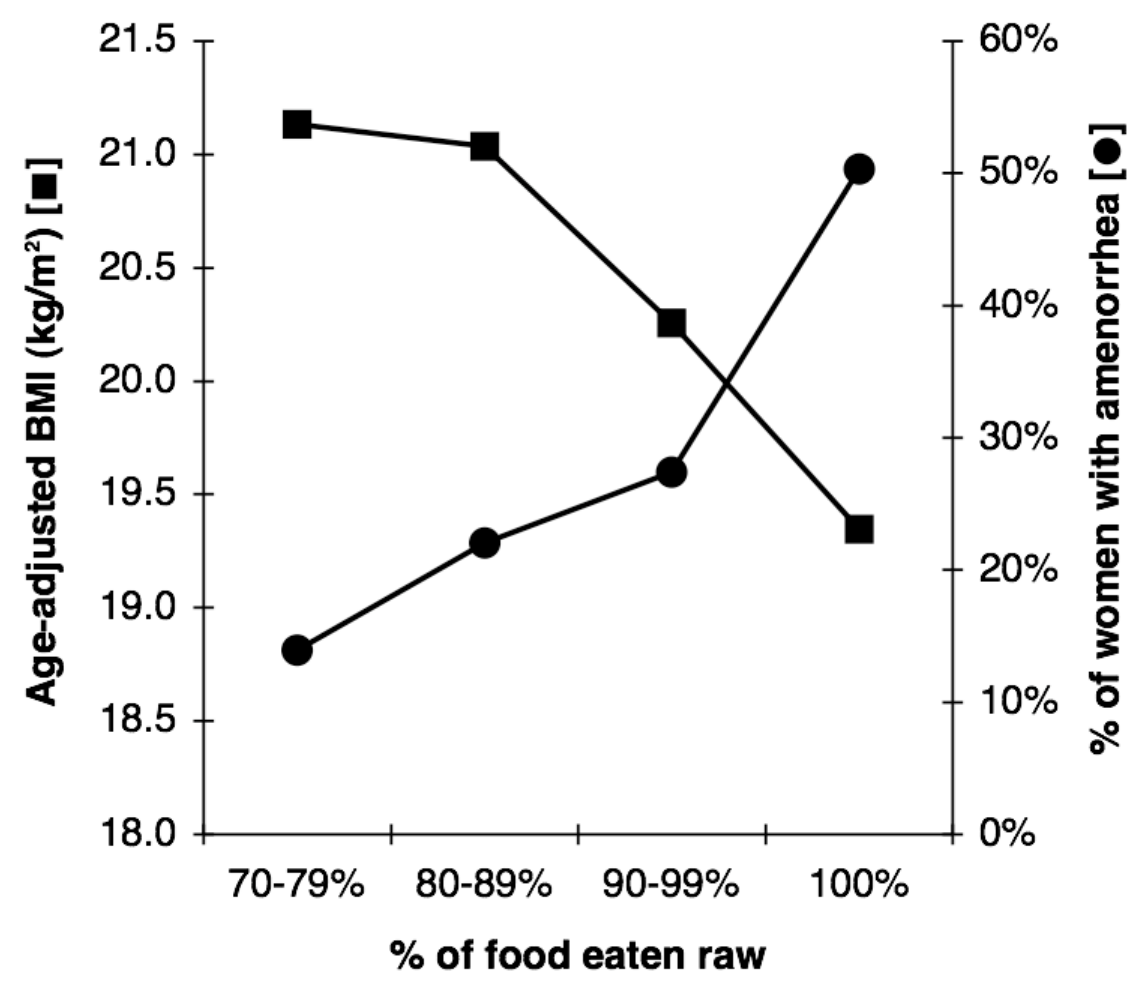

732 


\section{$733 \quad$ Figure 3.}

734

3a.

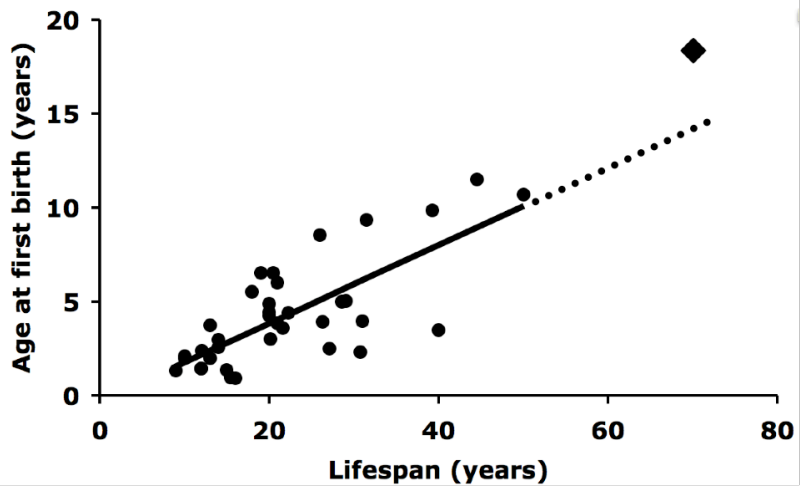

$3 c$.

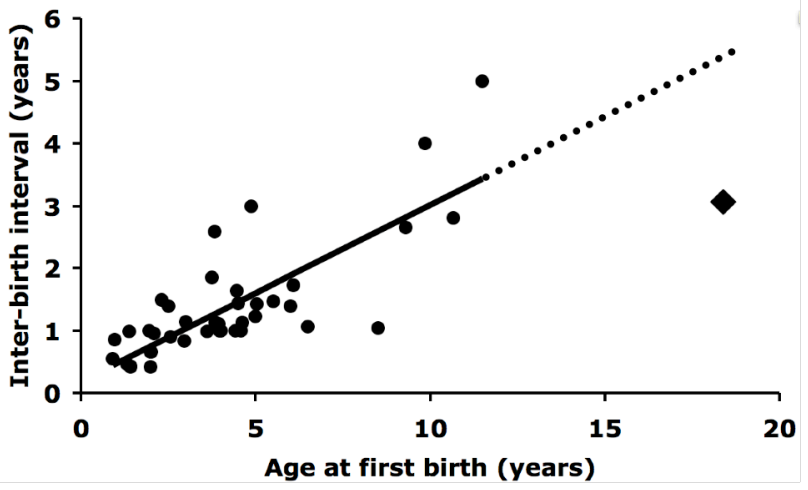

$3 b$.

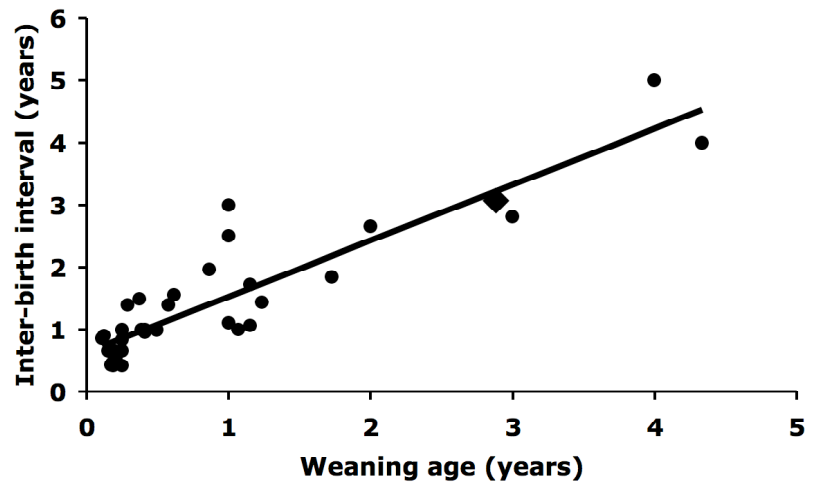

3d.

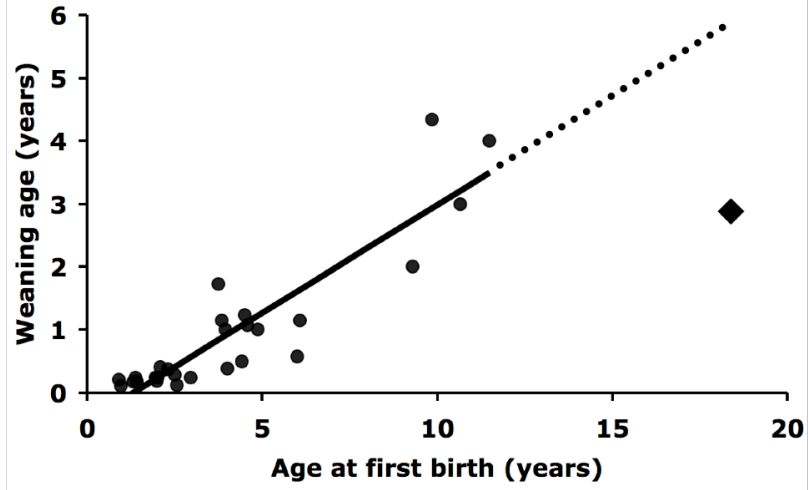


Figure 4.

737

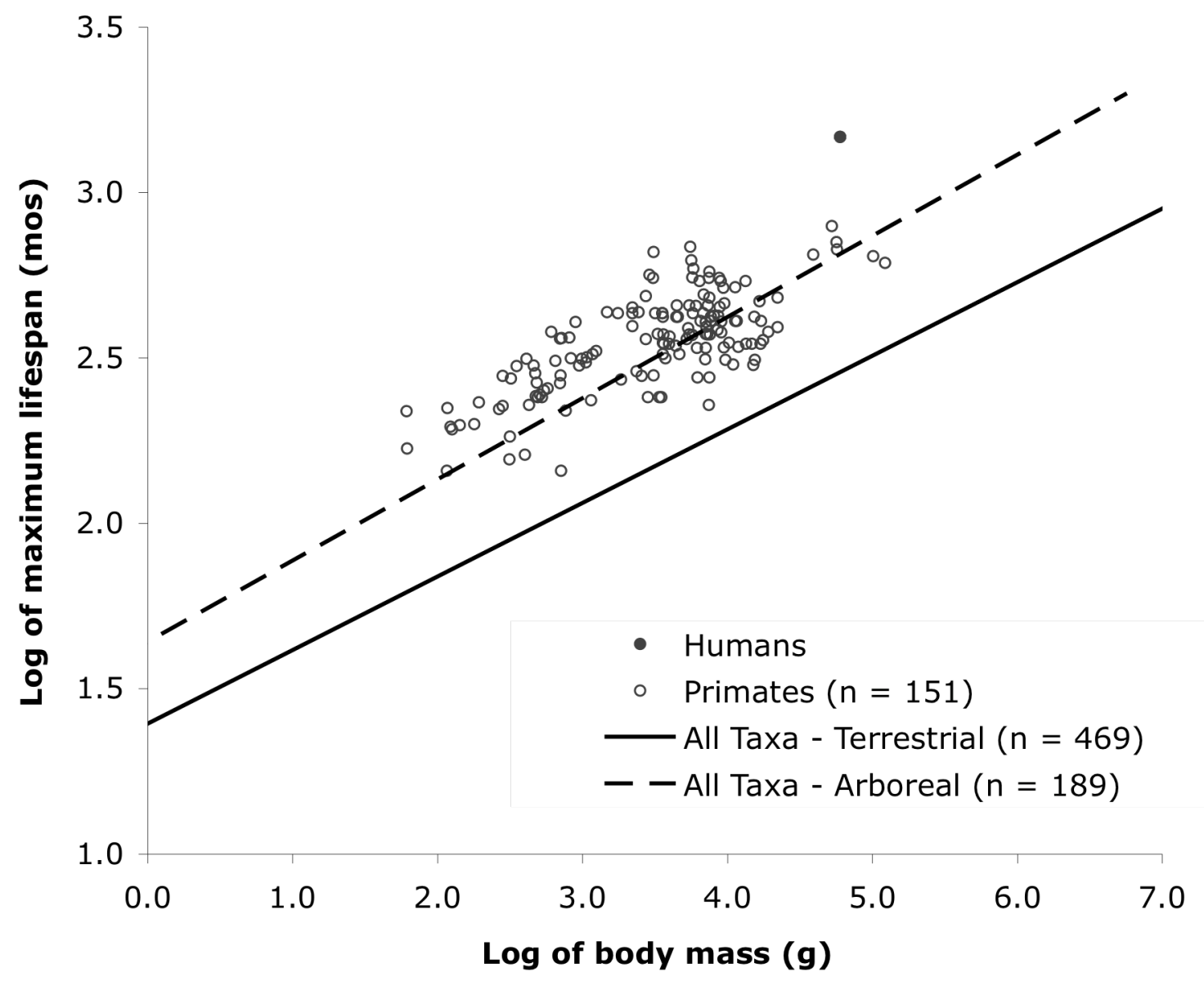


741 Figure 1. Baboon being prepared for cooking in a Hadza camp, northern Tanzania. Following a

742 widespread practice, the hunters have laid the prey on the fire in order to remove the hair by

743 singeing. After the hair has gone they sometimes leave the carcass on the fire and let it roast in

744 situ. Alternatively they boil the meat in a pot. Photograph and information courtesy of Frank W.

745 Marlowe.

747 Figure 2. Energy deficiency among raw-foodists, adapted from Koebnick and colleagues. ${ }^{10}$ Age-

748 adjusted body mass index (left axis, $\mathbf{\square}$ ) and percentage of non-pregnant female subjects $<45$

749 years old reporting amenorrhea (right axis, $\bullet$ ) as a function of the percent of the diet that is eaten

750 raw. The odds of energy deficiency or amenorrhea were not different for vegans, vegetarians and

751 meat-eaters in this sample.

752

753 Figure 3. The human life history puzzle. In most species different life history parameters are

754 consistent in their pace, as illustrated here for non-human primate species (solid circles) by

755 correlations among four life history variables. Unusually, hunter-gatherers (large diamond) are

756 slow in two variables (lifespan, age at first birth), but fast in two others (weaning, inter-birth

757 interval). Figure 3a: non-human primates with long maximum lifespan tend to have late age of

758 first birth $\left(r^{2}=0.56, n=36, p<0.001\right)$. Humans are here assigned a conservative estimate of 70

759 years for maximum lifespan, following Harvey and colleagues, ${ }^{92}$ and fall close to the primate

760 line. Figure 3b: non-human primates with later weaning have longer inter-birth intervals $\left(\mathrm{r}^{2}=\right.$

$7610.80, \mathrm{n}=36, \mathrm{p}<0.001)$. Hunter-gatherers conform to the primate trend. Figure 3c: non-human 
762 primates with a late age of first birth tend to have long inter-birth intervals $\left(r^{2}=0.61, n=41, p<\right.$

763 0.001); however hunter-gatherers have shorter inter-birth intervals than expected. Figure 3d:

764 non-human primates with a late age of first birth tend to wean later $\left(\mathrm{r}^{2}=0.82, \mathrm{n}=29, \mathrm{p}<0.001\right)$,

765 but hunter-gatherers have an earlier weaning age than expected. The puzzle about humans is why

766 they combine fast reproduction (short inter-birth interval and early weaning) with slow growth

767 (late age at first birth). Data sources: non-human primates, Harvey and colleagues ${ }^{92}$; hunter-

768 gatherers, Marlowe ${ }^{89}$ (Table 2, warm-climate, non-equestrian only). Number of hunter-gatherer

769 societies contributing to mean values: age at first birth, 6; inter-birth interval, 9; weaning age, 18.

770

771 Figure 4. Maximal lifespan plotted against body mass for humans (closed circle) and 151

772 primates (open circles), compared to the ordinary least squares regressions for 189 arboreal

773 mammals (dashed line: $\left.0.25 \mathrm{x}+1.64, \mathrm{r}^{2}=0.50, \mathrm{p}<0.001\right)$ and 469 terrestrial mammals $(\mathrm{y}=$

$\left.7740.22 \mathrm{x}+1.39, \mathrm{r}^{2}=0.76, \mathrm{P}<0.001\right)$. Modified from Figure 2 in Ref. 63 using data provided by

775 Shattuck and Williams. 


\section{Text Box}

Box 1. Summaries of three solutions to the human life history paradox: (1) the "grandmother hypothesis"; 60 (2) the "embodied capital model"; 58 and (3) the "control-of-fire hypothesis". The three solutions are not mutually exclusive.

Common framework. All three models share a framework in which reduced extrinsic mortality [1] is responsible for 'slow' aspects of human life history, notably slow maturation [2] and high longevity [3]. An inverse relationship between extrinsic mortality $(\mathrm{M})$ and time to maturity $(\alpha)$ is expected under Charnov's dimensionless approach to life history, in which $\alpha \mathrm{M}$ is approximately constant across related taxa. ${ }^{93}$ Slow maturation, in turn, promotes increased adult body mass.* Reduced extrinsic mortality will also favor increased longevity, as the average adult lifespan is roughly $1 / \mathrm{M} .{ }^{94}$ All three models also share the concept that the intensive provisioning of younger kin [4] allows for 'fast' aspects of human life history, including earlier weaning of infants [5] and an earlier return to fecundity by women post-weaning, which in turn favors a short interbirth interval [6] and high fertility overall. Whether stated or implied, all three models also infer that high fertility contributes to high longevity, since the inclusive fitness benefits that result from provisioning by older kin will act to strengthen natural selection on factors delaying senescence.

* Body mass increase in Homo is complicated by a reduction in sexual dimorphism, so that only females experience the increased mass. Reduction in sexual dimorphism in Homo is thought to be due to sexual selection, ${ }^{95}$ which we do not discuss in the present paper.
SLOW

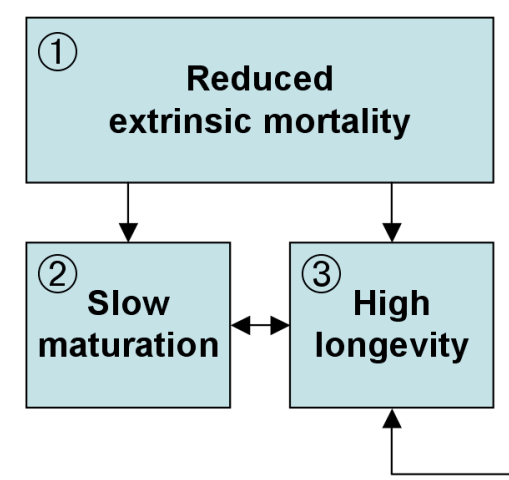

FAST

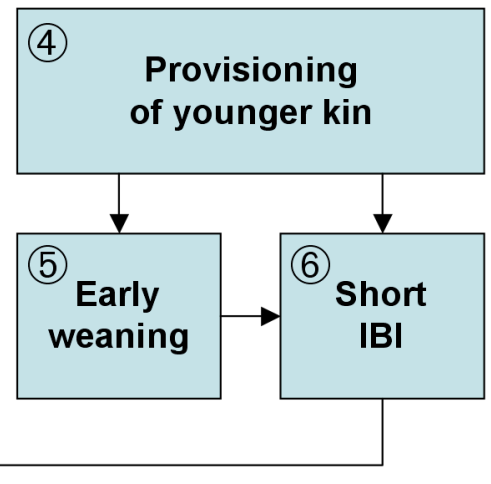


Grandmother hypothesis. ${ }^{\mathbf{6 0}}$ This model focuses on the inclusive fitness contributions of senior women as the critical factor allowing for high longevity and high fertility in humans.

Extractive foraging by skilled post-reproductive women generates food in excess of self-maintenance requirements [1] and this surplus is shared with juvenile relatives. This surplus food, as well as other contributions by post-reproductive women in the form of food processing and childcare, allows for higher fertility of reproductive-aged kin. Since inclusive fitness rises for postreproductive women who provision, 'long-lived helper' genes increase in frequency in the gene pool, contributing to longevity. In addition, continued provisioning by post-reproductive women lowers the susceptibility to disease [2] of juvenile kin, further selecting for increased longevity. Hawkes and colleagues argue that these relationships may explain the evolution of postmenopausal longevity in humans. ${ }^{60}$ The complementarity between the grandmother hypothesis and the control-of-fire hypothesis is illustrated by the fact that O'Connell and colleagues discussed the importance of cooking as a mechanism that helped enable provisioning of kin. ${ }^{77}$
SLOW

FAST

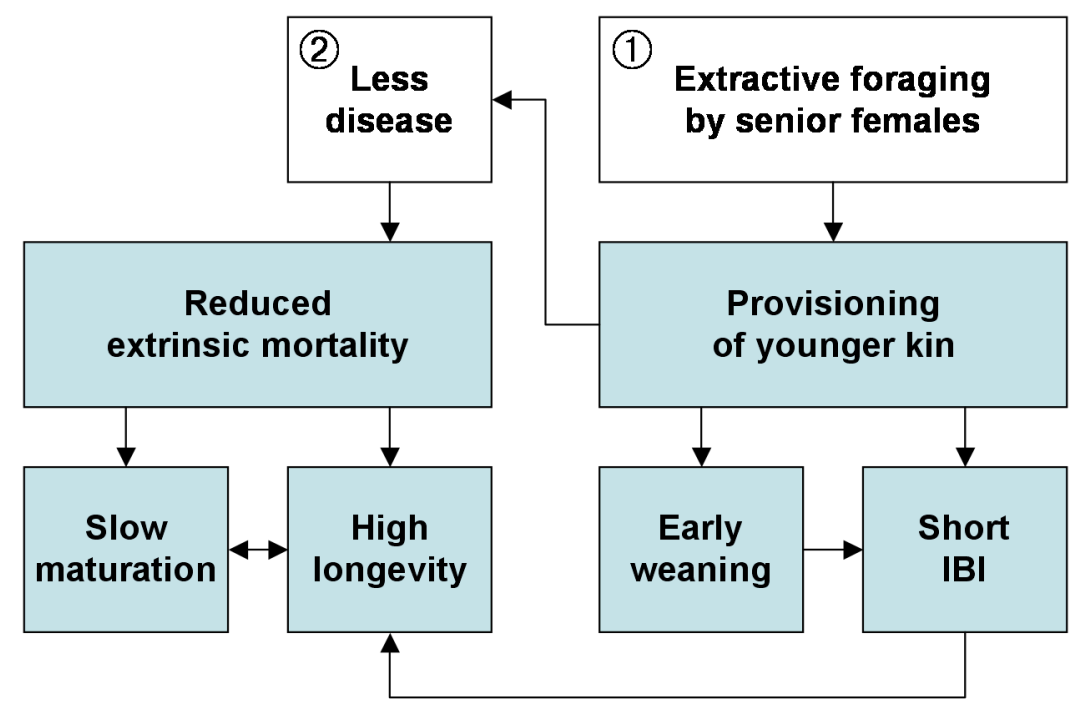


Embodied capital model. ${ }^{\mathbf{5 8}}$ This model emphasizes the time required to learn to subsist effectively on a diet of high-quality, nutrient-dense foods. Here, slow maturation allows for the acquisition of knowledge, skill and strength [1] that lead to profitable hunting and extractive foraging [2]. The productivity of older individuals far exceeds that of younger individuals, leading to a system of resource transfers from old to young within kin groups. In addition, since hunting is a low-success but high-return activity, a dietary niche that involves hunting favors a broader culture of food sharing [3] (kin-based and non-kin-based). Jointly, kin provisioning and food sharing act to minimize volatility in nutritional status, resulting in less disease [4]. In addition, such food transfers lead to less predation [5], since provisioning reduces the amount of time that juveniles must spend out of camp and since food sharing reduces the costs of group living, leading to larger group size. Increased knowledge, skill and strength can further limit predation as it allows for better defense. The resulting reduction in extrinsic mortality selects for the 'slow' aspects of human life history, with high longevity subject to especially strong selection because cumulative resource production increases nonlinearly with longevity. Kaplan and colleagues argue that these relationships lead to co-evolution between the human patterns of life history and extreme intelligence. ${ }^{58}$
SLOW

FAST

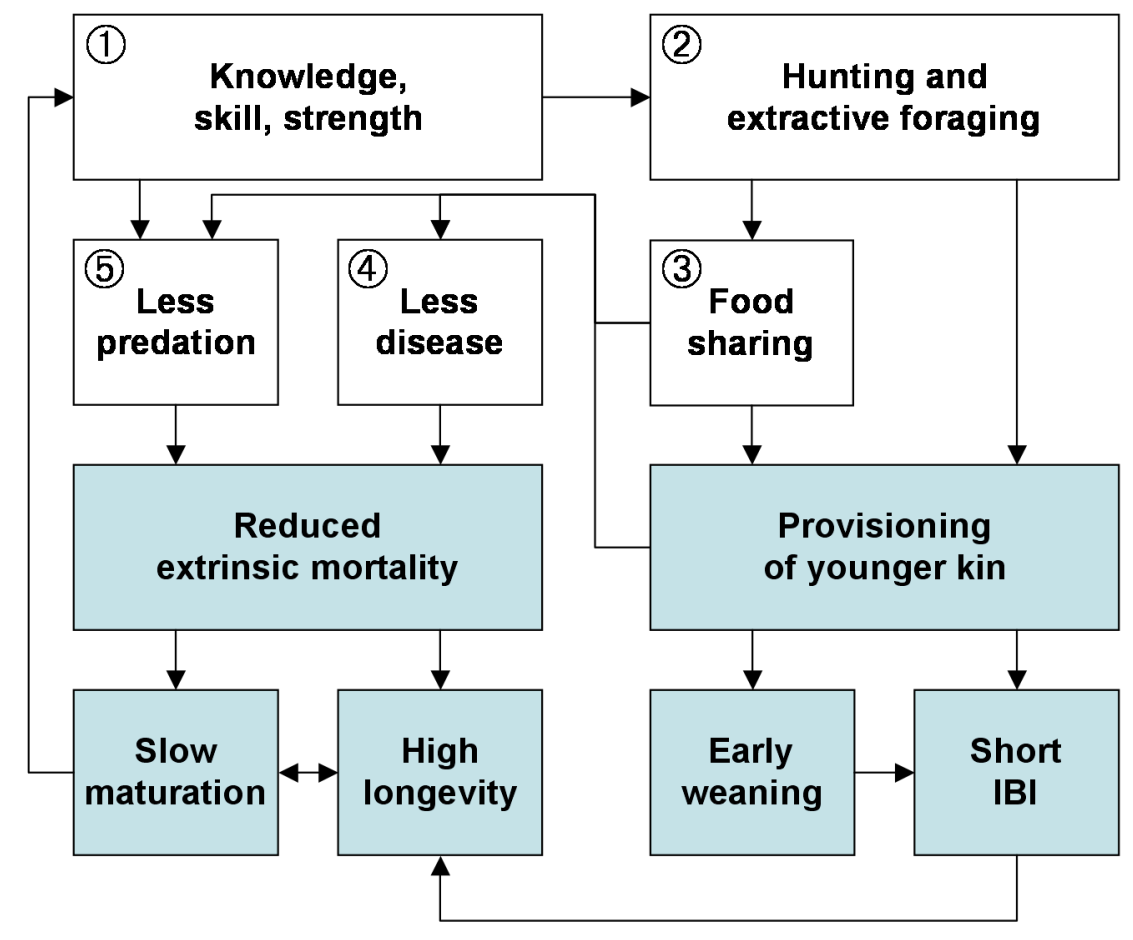


Control-of-fire hypothesis. We propose that the control of fire increases the efficiency of provisioning and reduces extrinsic mortality, thus contributing to the evolution of the human life history pattern. Increased efficiency of provisioning: Fire-use [1] allows for the cooking of food [2], which reliably enhances food energy, digestibility and softness [3] by the mechanisms discussed in this paper. Suitable infant foods are generated, allowing for earlier weaning. In addition, the high nutritive value of cooked food likely contributes to a short interbirth interval, given data illustrating the suppressive effect of a raw diet on ovarian function in modern raw-foodists. ${ }^{10}$ Importantly, the effects of cooking improve the efficiency of provisioning, with fewer raw resources required to achieve the same benefit. This enhances the value of kin provisioning, thus broadening the number of potential provisioners. Moreover, the act of cooking itself represents a means of contribution. This may enable juveniles who are not yet efficient hunters or foragers to contribute meaningfully to kin provisioning and thereby gain inclusive fitness benefits. Jointly, these characteristics favor the 'fast' aspects of human life history. Reduced extrinsic mortality: Other effects of cooking include food detoxification and the killing of foodborne pathogens. These features, coupled with a stable nutritional status as a result of a high-quality cooked diet and a culture of provisioning, lead to lower rates of disease [4]. Disease risk may be lessened further by fire-use, independently of the effects of cooking, if campsites are burned to eradicate pests. Finally, as discussed in this paper, fireuse results in less predation [5] due to the effects of fire as a predator deterrent and potential weapon. Jointly, the suppressive effects of fire-use on extrinsic mortality contribute to the 'slow' aspects of human life history.
SLOW

FAST

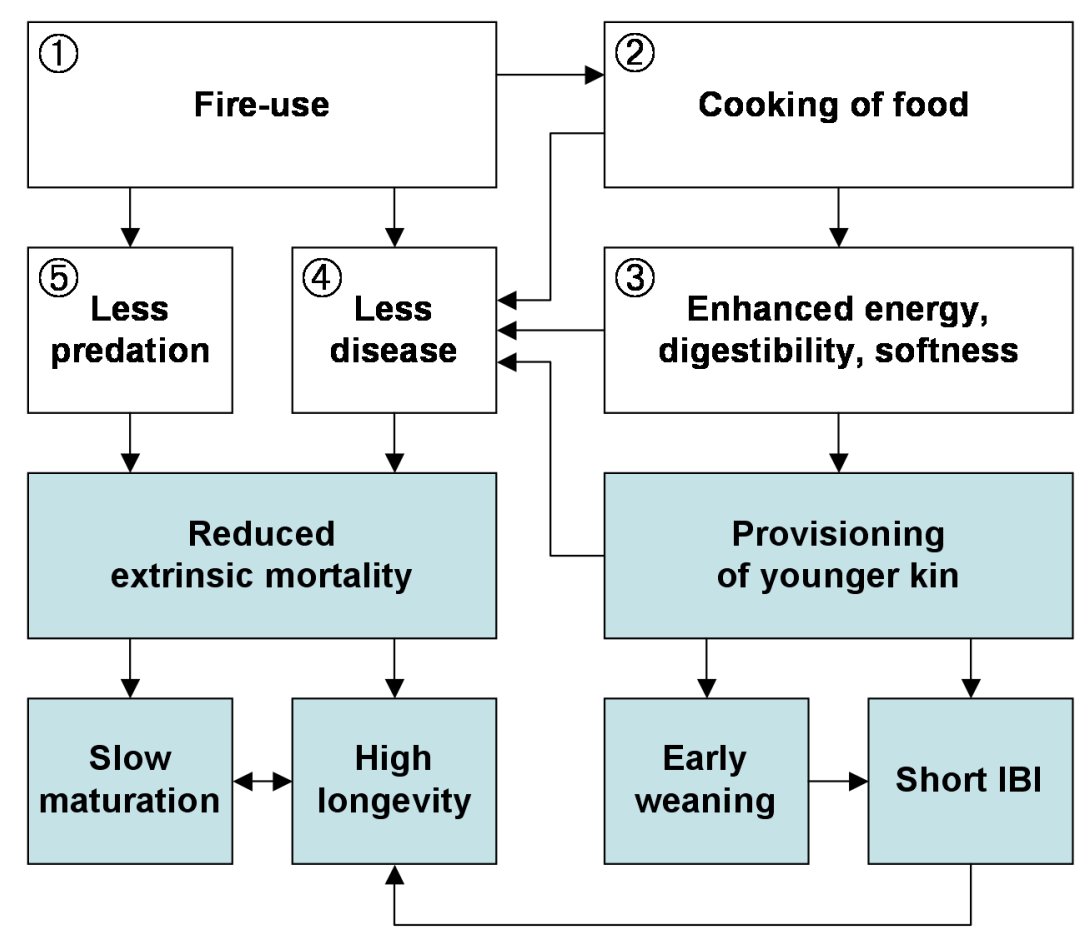

